\title{
Fluid-fluid levels in a soft-tissue tumour at MRI (2010: 3a)
}

(C) European Society of Radiology 2009

\section{Case report}

A diabetic 52-year-old man presented with a 1-year history of a painless, growing deep mass in his right thigh.

There was no prior history of trauma. Ultrasound revealed a big, deep intramuscular mass with lobular architecture containing dense fluid. MRI revealed a wellencapsulated mass $10 \mathrm{~cm}$ in size in the medial thigh within the right adductor muscles with hypointense rim on T2weighting. The internal structure had a complex multicystic aspect containing smaller cysts of variable high-signal intensity, with fluid-fluid levels, suggestive of proteinaceous or haemorrhagic contents. Marked enhancement of cystic walls was noted after injection of IV gadolinium. Peripheral oedema was observed in the soft tissues (Figs. 1, 2 and 3).

\section{What is the diagnosis?}

Readers are invited to supply one possible diagnosis via electronic means to: robert.hermans@uzleuven.be. The subject of the email should include 'Interpretation Corner' and the number given above (e.g. Interpretation Corner 2010: 3a). Responses should include name, title, address,

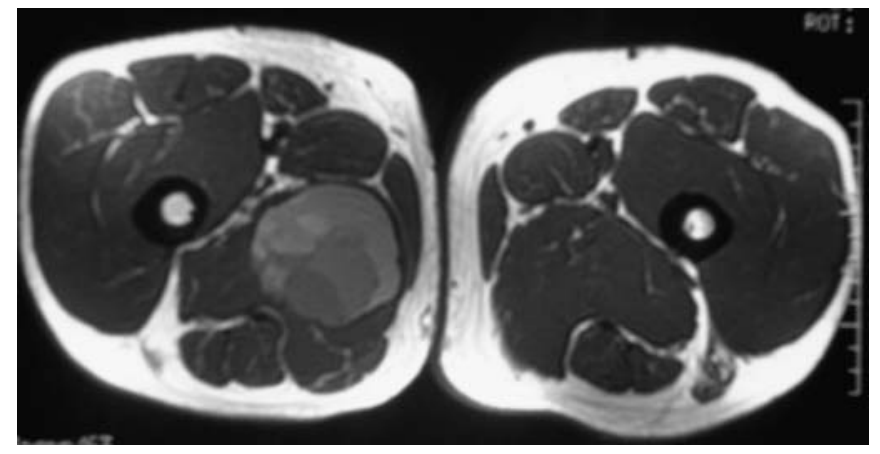

Fig. 1 Axial SE T1-weighted image
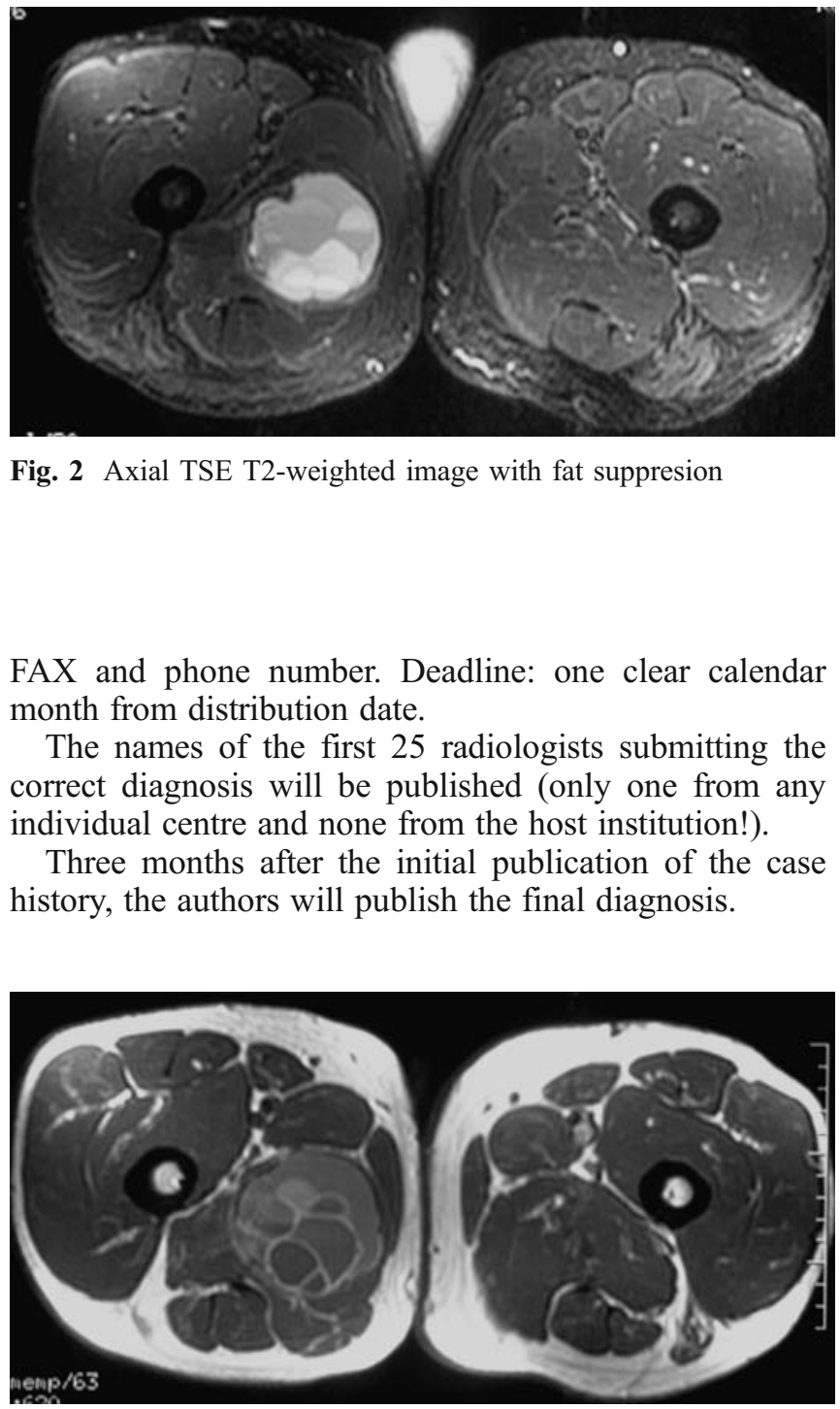

Fig. 2 Axial TSE T2-weighted image with fat suppresion

FAX and phone number. Deadline: one clear calendar month from distribution date.

The names of the first 25 radiologists submitting the correct diagnosis will be published (only one from any individual centre and none from the host institution!).

Three months after the initial publication of the case history, the authors will publish the final diagnosis.

Fig. 3 Axial SE T1-weighted with gadolinium 